\title{
The details of glycolipid glycan hydrolysis by the structural analysis of a family 123 glycoside hydrolase from Clostridium perfringens.
}

Ilit Noach ${ }^{1,3}$, Benjamin Pluvinage ${ }^{1,3}$, Cassandra Laurie ${ }^{1}$, Kento T. Abe ${ }^{1}$, Matthew G. Alteen ${ }^{2}$, David J. Vocadlo ${ }^{2}$ and Alisdair B. Boraston ${ }^{1, *}$

Keywords: $\beta$ - $N$-acetylgalactosaminidase, glycoside hydrolase, GH123, glycosphingolipid, ganglioside, globoside, substrate-assisted catalysis. 


\section{ABSTRACT}

25 Clostridium perfringens is an opportunistic pathogen of humans and animals whose genome 26 encodes a wide variety of putative carbohydrate-hydrolyzing enzymes that are increasingly being 27 shown to be directed towards the cleavage of host glycans. Amongst these putative enzymes is a 28 member of glycoside hydrolase family 123. Here we show that the recombinant enzyme 29 (referred to as $\mathrm{CpNga123)}$ encoded by the gene cloned from C. perfringens strain ATCC 13124 30 (locus tag $\mathrm{CPF}_{-} 1473$ ) is a $\beta-N$-acetylgalactosaminidase, similar to NgaP from Paenibacillus sp. 31 TS12. Like NgaP, CpNga123 was able to cleave the terminal $\beta$-D-GalNAc- $(1 \rightarrow 4)-D-G a l$ and $\beta$ 32 D-GalNAc- $(1 \rightarrow 3)-D-G a l$ motifs that would be found in glycosphigolipids. The X-ray crystal 33 structure of CpNga123 revealed it to have an N-terminal $\beta$-sandwich domain and a $(\beta / \alpha)_{8}$ barrel 34 catalytic domain with a C-terminal $\alpha$-helical elaboration. The structures determined in complex 35 with reaction products provide details of the -1 subsite architecture, catalytic residues, and a 36 structural change in the active site that is likely required to enable hydrolysis of the glycosidic 37 bond by promoting engagement of the substrate by the catalytic residues. The features of the 38 active site support the likelihood of a substrate-assisted catalytic mechanism for this enzyme. 39 The structures of an inactive mutant of CpNga123 in complex with intact GA2 and Gb4 40 glycosphingolipid motifs reveal insight into aglycon recognition and suggest that the kinked or 41 pleated conformation of GA2 caused by the $\beta$-1,4-linkage between $N$-acetylgalactosamine and 42 galactose, and the accommodation of this conformation by the enzyme active site, may be 43 responsible for greater activity on GA2. 


\section{INTRODUCTION}

51 Eukaryotic complex glycans are built primarily with the nine monosaccharide residues $N$ 52 acetylglucosamine, $N$-acetylgalactosamine, mannose, glucose, fucose, galactose, sialic acid, 53 xylose, and glucuronic acid. The use of these varied building blocks, which can be joined 54 through a number of different possible glycosidic linkages, leads to enormous diversity in a 55 given organism's glycome. The breakdown of these glycans, whether it is by normal host factors 56 or by colonizing microbes, is typically achieved through hydrolysis of the glycosidic linkages 57 and, because of the diversity of carbohydrate structures, requires an array of different enzymes. 58 These enzymes are part of a superfamily of proteins called glycoside hydrolases, which are 59 presently sub-classified into over 130 amino acid sequence-based families ${ }^{1}$. Collectively, the 60 specificities of the characterized glycoside hydrolases cover the hydrolysis of many of the known $61 \quad O$-glycosidic linkages. Surprisingly, however, an apparently underrepresented specificity 62 amongst glycoside hydrolases is specificity for $\beta$-linked $N$-acetylgalactosamine (EC 3.2.1.53).

$64 \beta$-linked $N$-acetylgalactosamine $(\beta$-GlcNAc) is found in some $N$ - and $O$-linked glycans, the 65 glycosaminoglycans chondroitin sulfate and dermatin sulfate, and is characteristic of the core 66 structures of the major vertebrate glycosphingolipids in the ganglioside and globoside 67 subfamilies ${ }^{2}$. Some enzymes, such as the human lysosomal $\beta$-hexosaminidases, are able to 68 hydrolyze terminal $\beta$-GalNAc residues, but these enzymes also typically cleave terminal $\beta-N$ 69 acetylglucosamine residues, and thus are classified as $\beta$-hexosaminidases (EC 3.2.1.52) ${ }^{3}$. 70 Presently, the only biochemically characterized $\beta$-N-acetylgalactosaminidase whose gene is 71 known and can be classified into a glycoside hydrolase family is the Paenibacillus sp. TS12 72 enzyme NgaP, which is the founding member of glycoside hydrolase family $123^{4}$. It possess no $73 \beta$ - $N$-acetylglucosaminidase activity and has preferential exo-hydrolytic activity on the $\beta$-D74 GalNAc- $(1 \rightarrow 3)$-D-Gal and $\beta$-D-GalNAc- $(1 \rightarrow 4)-D-G a l$ motifs found in the globoside and 75 ganglioside series of glycolipids, respectively. NgaP is proposed to achieve hydrolysis of the 76 glycosidic bond by a substrate-assisted mechanism ${ }^{5}$. The defining feature of this mechanism is 77 its utilization of the substrate acetamido oxygen as a nucleophile. A carboxylate containing 78 amino acid sidechain from NgaP must act as a general acid/base to donate a proton to the 79 glycosidic oxygen and aid departure of the leaving group, while a second carboxylate containing 80 amino acid sidechain would interact with the substrate acetamido nitrogen to help orient this 
81 group. At present, this mechanistic proposal is supported by the potent inhibition of NgaP by $N$ 82 acetyl-D-galactosamine-thiazoline (GalNGT), which is a mimic of the GalNAc oxazoline 83 intermediate, but currently lacks the details revealed by structural studies ${ }^{4}$.

85 Currently classified GH123 enzymes are limited to bacterial sources. In particular, those that are 86 host-adapted, such as members of the animal gut and oral microbiota, are heavily represented. A 87 gene present in some strains of Clostridium perfringens, which is a member of the human gut 88 microbiome and an opportunistic pathogen ${ }^{6,7}$, encodes a putative GH123 that was one of the 89 founding members of the GH123 family (locus tag CPF_1473 in the ATCC 1473 strain studied 90 here) ${ }^{4}$. The encoded protein remains uncharacterized but on the basis of its $34 \%$ amino acid 91 sequence identity with $\mathrm{NgaP}$ is hypothesized to be a $\beta-N$-acetylgalactosaminidase and therefore 92 potentially complement the array of known and putative $C$. perfringens enzymes that appear to 93 be directed at processing host glycans ${ }^{8}$. Here we tested the hypothesis that the activity of the $C$. 94 perfringens GH123 (referred to throughout as $\mathrm{CpNga123}$ ) is similar to that of NgaP. Further, we 95 used CpNga123 as a model system for structural studies to provide insight into the molecular 96 basis of substrate recognition and the mechanism of substrate hydrolysis by members of GH123. 97 


\section{RESULTS}

Activity of CpNga123 from Clostridium perfringens. CpNga123 (locus tag CPF_1473) from Clostridium perfringens ATCC 13124 is a 587 amino acid hypothetical protein that has 34\% amino acid sequence identity (over 389 residues) with the characterized $\beta-N$ acetylgalactosaminidase NgaP from Paenibacillus sp. TS12. Given this relationship, we anticipated the enzymatic activity of CpNga123 to be similar to that of NgaP. Towards examining this hypothesis, the complete open reading frame encoding CpNga123 was cloned as a fusion with an N-terminal six-histidine tag. The resulting recombinant polypeptide produced by E. coli was purified in two steps to yield protein suitable for both functional and structural studies. CpNga123 was screened against a panel of synthetic nitrophenyl glycosides of $\alpha$ - and $\beta$ D- $N$-acetylglucosamine, $\alpha$ - and $\beta$-D- $N$-acetylgalactosamine, $\alpha$ - and $\beta$-D-mannose, $\alpha$ - and $\beta$-Dglucose, $\alpha$ - and $\beta$-D-galactose, and $\alpha$-L-fucose. We only observed activity on 4-nitrophenyl $\beta$-D$N$-acetylgalactosaminide (pNP-GalNAc), consistent with our predicted function for CpNga123. 112 Using an endpoint activity assay the $\mathrm{pH}$ optimum of the enzyme was found to be between 5.2 113 and 5.8 and, subsequently, the determination of kinetic parameters was done at pH 5.5 (data not 114 shown). This analysis yielded a $K_{\mathrm{M}}$ of $261( \pm 43) \mu \mathrm{M}$ and a $\mathrm{V}_{\max }$ of $3.3( \pm 0.2) \mu \mathrm{mole} / \mathrm{L} / \mathrm{min}$. 115 Assuming fully functional enzyme, which was assayed at a concentration of $0.3 \mathrm{nM}$, this 116 calculates to a $\mathrm{k}_{\text {cat }}$ of $181( \pm 11) \mathrm{s}^{-1}$.

118 Glycan cleavage by CpNga123. We further probed the specificity of CpNga123 for $\beta$-linked $N$ D-acetylgalactosamine present internally or at the non-reducing terminus of model glycans using thin layer chromatography analysis of enzyme reactions. Such linkages are common in the globoside (Gb) and ganglioside (GA) series of glycans found on glycosphingolipids, leading us to test Gb4 [ $\beta$-D-GalNAc-( $1 \rightarrow 3)-\alpha-D-G a l-(1 \rightarrow 4)-\beta$-D-Gal-( $1 \rightarrow 4) \square \beta$-D-Glc], Gb5 [ $\beta$-D-Gal$(1 \rightarrow 3) \square \beta$-D-GalNAc-( $1 \rightarrow 3)-\alpha-D-G a l-(1 \rightarrow 4)-\beta$-D-Gal-( $1 \rightarrow 4) \square \beta$-D-Glc], GA1 [ $\beta$-D-Gal-( $1 \rightarrow 3)-$ $\beta$-D-GalNAc- $(1 \rightarrow 4)-\beta$-D-Gal-( $1 \rightarrow 4) \square \beta$-D-Glc], and $\quad$ GA2 $\quad[\beta$-D-GalNAc- $(1 \rightarrow 4)-\beta$-D-Gal$(1 \rightarrow 4) \square \beta$-D-Glc]. We also tested the blood-group H type IV tetrasaccharide $[\alpha-L-F u c-(1 \rightarrow 2)-\beta$ D-Gal-( $1 \rightarrow 3)-\beta$-D-GalNAc- $(1 \rightarrow 3) \square \beta$-D-Gal], which contains an internal $\beta$-linked GalNAc residue, and, as a negative control because it contains a terminal $\alpha$-linked GalNAc residue, the 
blood-group A type II tetrasaccharide $\{\alpha$-D-GalNAc- $(1 \rightarrow 3)[\alpha-L-F u c-(1 \rightarrow 2)]-\beta-D-G a l-$ $(1 \rightarrow 4) \square \beta$-D-Gal $\}$. We initially screened for a simple mobility shift by thin-layer 130 chromatography, which indicated reactions with only Gb4 and GA2 (Figure 1A). Comparison of 131 the reaction products with lactose $[\beta-\mathrm{D}-\mathrm{Gal}-(1 \rightarrow 4) \square \beta$-D-Glc] and Gb3 [ $\alpha$-D-Gal-( $1 \rightarrow 4)-\beta$-D132 Gal-(1 $\rightarrow 4) \square \beta$-D-Glc] standards revealed products from the GA2 and Gb4 reactions to have 133 migration properties consistent with those of lactose and Gb3, respectively, indicating cleavage of the terminal $\beta$-D-GalNAc residues (Figure 1B). The inability of CpNga123 to cleave GA1, Gb5, and the blood-group $\mathrm{H}$ type IV tetrasaccharide indicates the strict requirement of the enzyme for a terminal $\beta$-D-GalNAc. Under the conditions used, CpNga123 was unable to completely cleave Gb4 but it was able to completely convert GA2, suggesting a preference for terminal $\beta-(1 \rightarrow 4)-$ linked D-GalNAc residues.

The X-ray crystal structure of $\mathrm{CpNga123}$. CpNga123 crystallized in the spacegroup $\mathrm{P} 3{ }_{2} 21$ with a single molecule in the asymmetric unit and an initial structure was determined by the singlewavelength anomalous dispersion method using a selenomethionine-substituted preparation of the protein. The initial structure determined with $2.8 \AA$ resolution diffraction data, which was only built to approximately $70 \%$ completeness, was subsequently used to solve the structure of the protein from data collected to $1.5 \AA$ resolution on crystals of the protein in the spacegroup $\mathrm{P} 2{ }_{1} 2_{1} 2_{1}$ and with two molecules in the asymmetric unit. 580 contiguous residues of starting at residue 5 for chain A could be modeled and 579 contiguous residues also starting at residue 5 for chain B. This crystal was soaked in a cryoprotecting solution containing $1 \mathrm{M} \mathrm{KBr}$ and though data was collected at the wavelength for peak anomalous signal from bromide allowing over 100 bromide sites to be identified and modeled into anomalous difference maps, this was not ultimately used for phasing.

Overall, the structure of CpNga123 comprises $28 \beta$-strands and $19 \alpha$-helices arranged into two distinctly folded domains (Figure 2A). The N-terminal domain of approximately 160 amino acids adopts a twisted $\beta$-sandwich fold made up of two 5 -stranded $\beta$-sheets and accessorized with two small $\beta$-strands and four small $\alpha$-helices (Figure 2A). The most similar existing 
structures to this domain as determined by a structure similarity search with DALI ${ }^{9}$ are human hydin protein (PDB ID 2e6j, root mean square deviation of $2.0 \AA$ over 101 matched C $\alpha$ atoms, 9\% amino acid sequence identity, unpublished) and the E. coli periplasmic chaperone SfaE (PDB ID 114i, root mean square deviation of $2.2 \AA$ over 98 matched $\mathrm{C} \alpha$ atoms, $7 \%$ amino acid sequence identity, ${ }^{10}$ ).

The larger C-terminal domain of CpNga123 adopts a $(\beta / \alpha)_{8}$-barrel fold that is elaborated with a C-terminal pair of $\alpha$-helices and two-stranded $\beta$-sheet (Figure $2 \mathrm{~A}$ ). Further decorating the $(\beta / \alpha)_{8^{-}}$ barrel are two $\beta$-strands inserted between $\alpha$-helices 7 and 8 and a small $\alpha$-helix and two $\beta$ strands between $\alpha$-helices 10 and 11. The two $\beta$-strand inserts pair to form a four stranded $\beta$ sheet on the edge of the $(\beta / \alpha)_{8}$-barrel. A search for the closest structural homologs of this domain resulted in root mean square deviations in the range of $3.8-4.6 \AA$ (over $\sim 280$ match $\mathrm{Ca}$ positions; amino acid sequence identities of 8 to $12 \%$ ) with glycoside hydrolases in families 5 , 14, 30, 39, and 42. No particular enzyme family stood out as being more structurally similar, generally indicating little more than sharing the $(\beta / \alpha)_{8}$-barrel fold that is common to many glycoside hydrolase families.

CpNgal23 in complex with reaction products. To generate a complex with a product of catalysis native crystals of CpNga123 were soaked in excess GalNAc and diffraction data were collected to $2.15 \AA$ resolution. We found clear electron density for two GalNAc residues bound to each of the two CpNga123 monomers in the asymmetric unit. Both GalNAc binding sites were surface exposed and centered at opposing ends of barrel defining the center of the $(\beta / \alpha)_{8}$-barrel (Figure 2A). One of the bound GalNAc molecules made very few interactions with the protein and did not display the features of a typical protein-carbohydrate interaction, namely the very common $\mathrm{CH}-\pi$ interactions between carbohydrate rings and aromatic amino acid side chains (Figure $2 \mathrm{C}$ ). On this basis, we suggest this to be a secondary binding site that may be an artifact of the conditions used to obtain the crystal structure. The other GalNAc binding site, however, displayed the features expected of a carbohydrate-binding site (Figure 2A). The monosaccharide is nestled in a relatively apolar pocket marked by the presence of W180, W230, 
213 CpNga123 in complex with non-hydrolyzed substrates. NgaP is proposed to utilize a substrate 214

W459, W477, and Y423. W459 sits beneath the pyranose ring, packing against the plane formed by carbons $\mathrm{C} 3$ to $\mathrm{C} 6$. Indeed, this particular interaction appears to select for the axial $\mathrm{O} 4$ of GalNAc as the equatorial O4 of gluco-configured sugars would clash with W459. W477 sits above and slightly displaced to the side of the sugar to interact with C6. The acetamido group is sandwiched between W180 and Y423 with the plane of the acetamido group aligning with that of Y423 sidechain. The sugar makes relatively few direct hydrogen bonds with the protein: O6 hydrogen bonds with D481 and the backbone nitrogen of T426 while Q233 hydrogen bonds with $\mathrm{O} 3$ and O4, likely further selecting for the equatorial O4 of GalNAc. Additional water mediated hydrogen bonds involve bridging E345 and Y423 with the GalNAc O1, D344 and the acetamido nitrogen, D344 and W230 with O3, and the acetamido oxygen with the backbone carbonyl oxygen and backbone nitrogen of residues T424 and W459, respectively. O1 of the GalNAc residue is oriented towards a shallow groove that leads into the pocket that accommodates the monosaccharide suggesting the enzyme would accept additional monosaccharide units extending from $\mathrm{O} 1$. In contrast, the $\mathrm{C} 3$ to $\mathrm{C} 6$ side of the pyranose ring are proximal to the wall of the active site pocket, presumably preventing the recognition of additional sugars on the nonreducing end of the GalNAc. This provides identification -1 subsite of the CpNga123 active site that binds GalNAc and a molecular rationale for the exo-glycosidase activity of the enzyme.

In an effort to generate a Michaelis complex using the wild-type enzyme we soaked crystals for two minutes in 4-nitrophenyl 2-deoxy-2-difluoroacetamido- $\beta$-D-galactopyranoside. Despite the use of a short soak time and what was expected to be a poor substrate, the electron density in the active site of CpNga123 was consistent with the $N$-difluoroacetyl- $\beta$-D-galactosamine (GalNAc$\mathrm{F}_{2}$ ) product of catalysis in the same GalNAc binding site proposed to be the -1 subsite (Figure 4). The binding of GalNAc- $\mathrm{F}_{2}$ displayed three significant differences relative to the recognition of GalNAc: D344 made direct hydrogen bonds with O3 and the acetamido nitrogen of GalNAc- $\mathrm{F}_{2}$, E345 made a direct hydrogen bond with O1, and W289 moved in over the active site (Figure 3). assisted catalytic mechanism with amino acid pair D607 and E608 as catalytic residues ${ }^{4}$. 
Consistent with a role in catalysis, the analogous residues D344 and E345 in CpNga123 engage the acetamido nitrogen and $\mathrm{O} 1$, respectively, of GalNAc- $\mathrm{F}_{2}$. In order to generate a mutant of CpNga123 with sufficiently low activity to trap unhydrolyzed substrates in the catalytic site we generated a D344N/E345Q double mutant, which displayed undetectable activity on pNPGalNAc. Crystals of the CpNga123 double mutant were soaked with the GA2 trisaccharide and $\beta$-D-GalNAc- $(1 \rightarrow 3)-\mathrm{D}-\mathrm{Gal}$, which is the non-reducing terminal disaccharide of Gb4 (this will be referred to as the Gb4 disaccharide). In both cases, clear electron density allowed complete modeling of the intact sugars in the active sites of the single CpNga123 molecules in the asymmetric unit (Figure 4A and 4B).

CpNga123 monomers observed in the GA2 and Gb4 disaccharide complexes had root mean square deviations of $\sim 0.3 \AA$ when compared the in the native and GalNAc product complexes. Which also included insignificant differences in the backbone conformations in the region of the active site. Indeed, with the exception of the substituted catalytic residues D344N and E345Q, the positions of the amino acid side chains were virtually unchanged when comparing binding of the GalNAc product vs binding of the unhydrolyzed substrates. As expected, the nonreducing terminal GalNAc residue occupied the proposed -1 subsite with the reducing end of the sugars extending out of the active site (Figure 4A and 4B). Often, such an approach to trapping unhydrolyzed substrates in the active sites of glycoside hydrolases results in obtaining Michaelis complexes, which for a $\beta$-glycosidase such as CpNga123 would enable visualization of the distorted sugar in the -1 subsite. In this case, no significant distortion of the GalNAc residue was observed for either substrate complex. While we would expect substrate distortion for a true Michaelis complex of CpNga123, that we did not observe this is likely due to the necessity of creating mutations at both of the catalytic residues in order to the reduce the activity of the enzyme enough to trap unhydrolyzed substrate complexes. Indeed, the positions of the mutated catalytic residues were the only significant difference between the two substrate complexes and in neither case did these mutated residues make substantial interactions with the substrate: D344N made a single water mediated hydrogen bond in the Gb4 disaccharide complex (Figure 4B) while in the GA2 complex both D344N and E345Q were oriented completely out of the active site in the (Figure 4A). 
3

4245

6

7246 The additional sugar residues of GA2 and the Gb4 disaccharide made very few additional 8 interactions with the enzyme. The $\beta$-1,4-linkage between the terminal GalNAc and central Gal of GA2 create a kink in this sugar causing it to point out of the active site with only an additional water mediated set of hydrogen bonds between $\mathrm{O} 2$ and $\mathrm{O} 3$ of the Gal and the backbone nitrogen of E453Q (Figure 4A). In contrast, the involvement of all axial groups in the $\beta$-1,3-linkage of the Gb4 disaccharide result in its planar conformation, causing it to sit deeper in the active site and engage H398 and D376 in hydrogen bonding with O1 of the Gal residue (Figure 4B). 


\section{DISCUSSION}

The substrate-assisted catalytic mechanism used by glycoside hydrolases depends on the presence of a $\mathrm{N}$-acetylhexosamine residue whose acetamido group oxygen acts as a nucleophile to attack $\mathrm{C} 1$ of the same residue ${ }^{5,11}$. The enzyme typically employs a contiguous pair of amino acids with carboxylate-containing side chains. One residue acts as general acid to donate a proton to the glycosidic oxygen and aid departure of the leaving group while the second carboxylate residue interacts with the acetamido nitrogen to stabilize the position of this group and polarizes the group to facilitate nucleophilic attack at $\mathrm{C} 1$. A notable feature of this mechanism is the formation of a bicyclic oxazoline intermediate. Sumida et al. observed that a mimic of a putative GalNAc oxazoline intermediate, GalNGT, is nanomolar inhibitor of NgaP, while the enzyme also possesses an Asp-Glu dyad that is conserved in the family and is critical to catalysis ${ }^{4}$. These features led Sumida et al. to propose that $\mathrm{NgaP}$ and other members of GH123 use substrate-assisted catalysis to achieve cleavage of the glycosidic bond, a hypothesis that our structural data supports.

In all of the complexes that we obtained, and as exemplified by the GalNAc- $F_{2}$ complex, the residue occupying the -1 subsite was poised with the acetamido group positioned beneath the plane of the pyranose ring (Figure 5). While the acetamido oxygen was not observed directly beneath $\mathrm{C} 1$, and therefore not immediately in position for nucleophilic attack, its placement was consistent with a trajectory of migration towards being positioned for attack and, in general, is quite similar to the position of acetamido groups observed in the Michaelis complexes of enzymes that use substrate-assisted catalysis ${ }^{12-15}$. Furthermore, there were no other amino acid sidechains suitably placed to act as a nucleophile. Thus, this characteristic of the CpNga123 complexes supports the substrate-donated nucleophile component of the proposed substrateassisted mechanism. Use of this mechanism also predicts that D344 would interact with the acetamido nitrogen while E345 would act as the acid-base residue. Surprisingly, in our GalNAc, GA2, and Gb4 disaccharide complexes neither of these residues were suitably positioned to perform their proposed roles and either interacted with the carbohydrate via water molecules or not at all. However, our acquisition of the GalNAc- $\mathrm{F}_{2}$ product complex provides insight into this ambiguity. The recognition of GalNAc- $F_{2}$ is achieved with an altered active site conformation 
resulting in D344 and E345 moving further into the active site and engaging the carbohydrate in a manner consistent with their proposed roles in the catalytic mechanism: E345 is positioned to hydrogen bond with $\mathrm{O} 1$ (the glycosidic oxygen) while D344 hydrogen bonds with the acetamido nitrogen (Figure 5). Therefore, the architecture of the CpNga123 active site and mode of carbohydrate recognition are most consistent with a substrate-assisted mechanism of glycosidic bond hydrolysis; however, this appears to be accompanied by a necessary conformational transition.

The backbone conformation of the active sites of the native, GalNAc, GA2, and Gb4 disaccharide complexes were very similar (not shown). In contrast, a significant structural change involving residues $287-382$ accompanied binding of GalNAc- $\mathrm{F}_{2}$, resulting in the "engaged" conformation of the active site (Figure 6A). The conformational shift in this region included W289 to flipping into the active site while the $\beta 20-\gamma 1-\alpha 13$ domain (residues 339-360), where the $\gamma$-turn contains D344 and E345, presses an additional $\sim 2.5 \AA$ into the active site promoting the engagement of the carbohydrate by these residues (Figure 6A). Overall, these structural differences resulting in the transition from the relatively open active site seen in the GalNAc complex (Figure 6B) to the more closed engaged active site seen in the GalNAc- $F_{2}$ complex (Figure 6C).

Given that the $\beta 20-\gamma 1-\alpha 13$ is one of the composite domains of the $(\beta / \alpha)_{8}$-barrel it might be expected to be relatively conformationally constrained. Indeed, this region of the protein showed only minimally elevated B-factors relative to the core of the $(\beta / \alpha)_{8}$-barrel in the GalNAc and GA2 bound forms of the enzyme (Figure 6D and 6E). In contrast, this domain, and all residues from 287-382, showed significantly elevated B-factors in the GalNAc- $F_{2}$ complex (Figure 6F). This latter structure was determined in the same spacegroup as for the GA2 complex, albeit with slightly different cell dimensions but with nearly indistinguishable crystal packing (not shown). This suggests that the elevated mobility of residues 287-382 is associated with the formation of 310 the engaged active site, rather than an alteration in the crystal packing. 
In addition to the movement of the $\beta 20-\gamma 1-\alpha 13$ domain, which brings the catalytic residues into the active site, the structural alterations upon GalNAc- $\mathrm{F}_{2}$ binding includes a rearrangement in the $\beta$-strand pairing between $\beta 20$ and $\beta 21$, causing the $\beta 21$ strand to lengthen and also move it, and the beginning of the loop following this strand, closer to the active site. The loop that follows $\beta 21$, which comprises residues 374-382, is ordered in all of structures except the GalNAc- $\mathrm{F}_{2}$ structure yet is generally characterized by elevated B-factors relative to the rest of the structure (Figure 6D and 6E). In the GalNAc- $\mathrm{F}_{2}$ complex, this loop is completely disordered from residues 378-382 (Figure 6F). Despite this apparent destabilization of the loop during the formation of the engaged active site, we suggest that the movement of this loop, particularly its effect on positioning D376, may play a role in substrate recognition (see below).

322 On the basis of these observations we suggest that the resting state of the CpNga123 active site 323 has a conformation that is not catalytically competent. Upon carbohydrate recognition, the 324 secondary structure elements adjacent to the active site, but distal to the $N$-terminal $\beta$-sandwich 325 326 module, undergo some movement and rearrangement such that the active site adopts an engaged conformation to position the catalytic residues appropriately to assist bond cleavage through a substrate-assisted catalytic mechanism. A similar structural change was recently observed in the active site of GH20C from Streptococcus pneumoniae, which also uses a substrate-assisted catalytic mechanism, though the structural rearrangements were on a significantly smaller scale requiring only the movement of relatively small loop containing the catalytic residues to engage the substrate ${ }^{16}$.

The specificity of CpNga123 for terminal $\beta$-linked GalNAc residues is relatively rare among glycoside hydrolases. $\beta-N$-acetylgalactosaminidase activity is also found in some members of glycoside hydrolase family 20 , such as HexA, HexB, and GH20C ${ }^{3,16}$. However, these enzymes also have significant $\beta-N$-acetylglucosaminidase activity, which the characterized members of GH family 123 (NgaP and CpNga123) lack. Our recent structural analysis of GH20C from Streptococcus pneumoniae indicated that the enzyme is able to maintain the same hydrogen bonding with $\mathrm{O} 4$ regardless of whether it is in the axial or equatorial position, thus resulting in 
no selectivity for GalNAc or GlcNAc. In contrast, in CpNga123 Q233 is positioned such that it could only hydrogen bond an axial O4, while an equatorial O4 would clash with W459, all providing selectivity for the axial O4 of GalNAc (Figures 2, 3, and 4).

As was found for NgaP, our results suggested that $\mathrm{CpNga1} 23$ preferred the terminal $\beta$-1,4-linked GalNAc of GA2 over the terminal $\beta$-1,3-linked GalNAc of Gb4. Our complexes of the D344N/E345Q double mutant with GA2 and the Gb4 disaccharide were obtained with the unengaged conformation of the active site (i.e. catalytic residues retracted); however, overlaying these complexes with the GalNAc- $\mathrm{F}_{2}$ product complex reveals some insight into aglycon recognition. Though D344 in the engaged form of the active site would be positioned to interact with the acetamido nitrogen, E345 would clash with the aglycon for both substrates (Figure 7A and 7B). Thus, in a true Michaelis complex, E345 would require a modest repositioning to locate it properly to donate a proton to the glycosidic oxygen. Similarly, the lengthening of $\beta 21$ and repositioning of the loop that follows it places the loop, and in particular D376, in the path of the aglycon. In this engaged conformation, D376 would clash with the galactose residue of Gb4 (Figure 7A). CpNga123 does possess some activity on $\mathrm{Gb} 4$ and, thus, this clash is not catastrophic to the activity of the enzyme but it appears to be enough to reduce it in our qualitative assay. The somewhat plastic nature of this region of the protein may allow it to accommodate $\mathrm{Gb} 4$ with the catalytic residues appropriately positioned but the loop containing D376 in an alternate conformation to that seen in the engaged conformation of the active site. In contrast, the $\beta-1,4$-linkage between the terminal GalNAc and preceding galactose in GA2 results in a kinked conformation by virtue of the axial $\mathrm{O} 4$ of the galactose. This would place the sugar on a path that avoids a clash with D376, perhaps enabling optimal recognition and activity on GA2 (Figure 7B). Though this accommodation in the active site appears to provide recognition of the sugar portion of the aglycon there are no obvious features revealed by an examination of the surface of CpNga123 that would suggest specific recognition of the lipid portion of a glycolipid. We consider this consistent with the observation that CpNga123 from C. perfringens lacks a predicted secretion signal and therefore likely operates in the cytoplasm of the bacterium on glycans previously released by another unidentified enzyme and imported by a sugar transporter. 
7371 Glycoside hydrolase family 123 appears to be a unique GH family as its two characterized 9372 members are restricted to $\beta$ - $N$-acetylgalactosaminidase activity (EC 3.2.1.53) as opposed to the 10 relatively common $\beta$ - $N$-acetylglucosaminidase activity (EC 3.2.1.52) and $N$ acetylhexosaminidase activity (possessing both $\beta$ - $N$-acetylgalactosaminidase and $\beta-N$ acetylglucosaminidase activities; EC 3.2.1.52). Terminal $\beta$-linked $N$-acetylgalactosamine residues are largely found in glycosphingolipids, therefore suggesting that these glycoconjugates are the likely substrates for the known GH123 enzymes. C. perfringens, the source of the GH123 enzyme studied herein, is a common member of the human gut microbiome and an opportunistic pathogen that has an array of carbohydrate-active enzymes whose known or predicted activities target complex eukaryotic glycans (see, for example ${ }^{17-21}$ ). The observed $\beta-N$ acetylgalactosaminidase activity of the CpNga123 may complement this enzymatic arsenal by adding further capability to depolymerizing glycolipid glycans and thereby potentially contribute 383 to the host-microbe interaction. 


\section{MATERIALS AND METHODS}

Materials. All reagents and chemicals were from Sigma, unless otherwise stated.

386 Gene cloning, protein expression and purification. The gene fragment encoding CpNga123 387 (locus tag CPF_1473, amino acids 1-587) was PCR-amplified from Clostridium perfringens ATCC 13124 genomic DNA using the oligonucleotide primers GH123-Fw (5'CAGCCATATGGCTAGCATGAAAAAAGATACTACTCTTGGTGCT) and GH123-Rv (5'GGTGGTGGTGCTCGAGCTACAAGGTTTCCATAGTTAATGAAATAA). The amplified DNA fragment was cloned into pET 28a (Novagen) using the Infusion HD cloning kit (Clontech) according to the manufacturers instructions. The resulting plasmid, pGH123, encoded the desired polypeptide fused to an N-terminal six-histidine tag by a thrombin protease cleavage site. Sitedirected mutagenesis to introduce the D344N/E345Q double mutation was performed using the Mut-Fw (5'-AaCCAGAGAagtATGGatgatTtaAaAGCTTGTG-3') and Mut-Rv (5'CATACTTCTCTGGTTCATTGAAATATAAGTTATGTTAAACC-3') mutagenic primers and Infusion HD cloning kit according to the manufacturers instructions. The DNA sequence fidelity of all constructs was verified by bidirectional sequencing.

Escherichia coli strain BL21 (Invitrogen) transformed with the pGH123 plasmid was grown in $4 \mathrm{~L}$ of sterile LB media with $50 \mu \mathrm{g} / \mathrm{mL}$ of kanamycin with shaking at $37^{\circ} \mathrm{C}$ until an OD $600 \mathrm{~nm}$ of $\sim 0.8$ was reached. Cells were then cooled at $16^{\circ} \mathrm{C}$ for one hour. Isopropyl $\beta-\mathrm{D}-1-$ thiogalactopyranoside (IPTG) was added to a final concentration of $0.5 \mathrm{mM}$ to induce recombinant protein expression followed by overnight incubation at $16^{\circ} \mathrm{C}$ with shaking. The cells were harvest by centrifugation at $5000 \times \mathrm{g}$ for $10 \mathrm{~min}$ at $12{ }^{\circ} \mathrm{C}$. The bacterial cells were chemically lysed by the addition of a sucrose solution (25\% sucrose with $20 \mathrm{mM}$ Tris- $\mathrm{HCl} \mathrm{pH}$ 8), $0.66 \mathrm{mg} / \mathrm{mL}$ of lysozyme, a deoxycholate solution (1\% deoxycholate, $50 \mathrm{mM}$ Tris- $\mathrm{HCl} \mathrm{pH} 8$, $100 \mathrm{mM} \mathrm{NaCl}$, and $1 \%$ Triton $\mathrm{X} 100$ ), and $\mathrm{MgCl}_{2}$ and DNAse ${ }^{22}$. The clarified cell lysate was loaded onto an a $\mathrm{Ni}^{2+}$-NTA immobilized metal affinity chromatography column. The polypeptide was eluted from the column with binding buffer ( $20 \mathrm{mM}$ Tris, $\mathrm{pH} 8.0,500 \mathrm{mM} \mathrm{NaCl}$ ) containing increasing imidazole concentrations, ranging from 5 to $500 \mathrm{mM}$. Fractions containing pure protein as judged by SDS-PAGE analysis on $15 \%$ gels were pooled and concentrated using a 
stirred ultra-filtration unit (Amicon, Beverly, MA) with a $10 \mathrm{kDa}$ cut-off membrane (Filtron, Northborough, MA). The concentrated protein was loaded onto a Sephacryl S-200 HR sizeexclusion column in $200 \mathrm{mM}$ Tris and $0.5 \mathrm{M} \mathrm{NaCl}$, and fractions containing the protein were pooled and concentrated using the ultrafiltration unit. The concentration of the protein was determined by absorbance at $280 \mathrm{~nm}$ using the calculated molar extinction coefficient of 143950 $\mathrm{M}^{-1} \mathrm{~cm}^{-123}$.

The methionine auxotrophic strain E. coli B834 (DE3) (Novagen) transformed with the pGH123 plasmid was grown in $4 \mathrm{~L}$ of seleno-methionine labeling media prepared according to the manufacturers instructions (AthenaES). The procedure for protein expression and purification was otherwise performed as for the native protein.

Enzyme activity assays. CpNga123 at $1 \mu \mathrm{M}$ was screened for activity against a small panel of synthetic substrates comprising 4-nitrophenyl- $N$-acetyl- $\beta$-D-galactosaminide (pNP-GalNAc), 4nitrophenyl- $N$-acetyl- $\alpha$-D-galactosaminide, the $\alpha$ and $\beta$-anomers 4-nitrophenyl- $N$-acetyl-Dglucosaminide, the $\alpha$-and $\beta$-anomers of 4-nitrophenyl-D-glucopyranoside, the $\alpha$-and $\beta$-anomers of 4-nitrophenyl-D-mannopyranoside, the $\alpha-$ and $\beta$-anomers of 4-nitrophenyl-Dgalactopyranoside, and 4-nitrophenyl- $\alpha$-L-fucopyranoside at $\mathrm{pH} 7.2$ in PBS using the generation of absorbance at $400 \mathrm{~nm}$ as a qualitative readout. The substrates were used at a final concentration of $1 \mathrm{mM}$. The activity of CpNga123 on pNP-GalNAc was tested at $12 \mathrm{pHs}$ of McIlvaine buffer $(0.114 \mathrm{mM}$ sodium disphosphate and $0.0431 \mathrm{mM}$ citric acid) over the $\mathrm{pH}$ range of 2.9 to 7.5 to determine the optimum $\mathrm{pH}$. Quadruplicate reactions at each $\mathrm{pH}$ were performed in 96 well plates in a final reaction volume of $110 \mu \mathrm{L}$ per well containing $5 \mathrm{nM} \mathrm{CpNga123,1 \%}$ $\mathrm{BSA}$, and $1 \mathrm{mM}$ pNP-GalNAc. Reactions were incubated at $37^{\circ} \mathrm{C}$ for 15 minutes then stopped with $150 \mu \mathrm{L} 0.1 \mathrm{M} \mathrm{NaOH}$ and the absorbance read at $400 \mathrm{~nm}$ with a Spectramax M5 plate reader using Softmax pro 6.2.1 software (Molecular Devices). Kinetic analyses done using a discontinuous assay in Mcllvaine buffer at $\mathrm{pH}$ 5.5. Triplicate reactions containing a range of

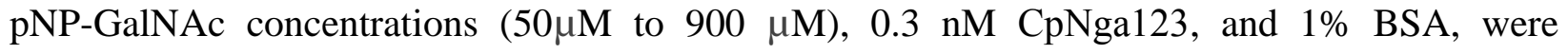


incubated at $37^{\circ} \mathrm{C}$ with stirring. $100 \mu \mathrm{L}$ aliquots were taken each minute for 7 minutes, to which $150 \mu \mathrm{L} 0.1 \mathrm{M} \mathrm{NaOH}$ was added. These samples were read in 96 well plates as above. An extinction coefficient of $18300 \mathrm{M}^{-1} \mathrm{~cm}^{-1}$ was used to convert absorbance at $400 \mathrm{~nm}$ to concentration of 4-nitrophenol produced by the reaction.

Reactions for analysis by thin layer chromatography contained $5 \mathrm{mM}$ sugar, $2 \mu \mathrm{M}$ CpNga123, and McIlvaine buffer in a final reaction volume of $10 \mu \mathrm{L}$. Controls lacking enzyme were performed for each sugar. Digests were incubated overnight at $37^{\circ} \mathrm{C} .4 \mu \mathrm{L}$ of each digest was spotted onto a silica gel thin layer chromatography plate. Reactions were separated by in a solvent comprising butanol:acetic acid:H2O (2:1:1, v/v/v). A sulfuric acid/ethanol (1:20, v/v) solution was used to develop the TLC plate at $110{ }^{\circ} \mathrm{C}$ for 15 minutes.

$X$-ray crystal structure determination. Crystals of $\mathrm{CpNga123}$ were obtained at $18^{\circ} \mathrm{C}$ using sitting-drop vapor diffusion for screening and hanging drop vapor diffusion for optimization. In all cases 1:1 protein to crystallization CpNga123 ratios were used and, unless otherwise specified, the protein was at $20 \mathrm{mg} / \mathrm{ml}$. Native CpNga123 at $47 \mathrm{mg} / \mathrm{ml}$ and selenomethioninesubstituted CpNga123 (Semet- CpNga123) crystallized in $0.20 \mathrm{M}$ sodium formate, 11\% (w/v) polyethylene glycol 3350, and 0.1 M HEPES, pH 7. Crystals of CpNga123 in complex with GalNAc were obtained by soaking native crystals grown in $0.18 \mathrm{M}$ sodium formate, $17 \%$ (w/v) polyethylene glycol 3350, and 0.1 M HEPES, $\mathrm{pH} 7$, in crystallization solution supplemented with >10 mM GalNAc. Crystals of CpNga123 in complex with 4-nitrophenyl-2-fluoroacetyl- $\beta$ D-galactosaminide were obtained by soaking native crystals grown in $0.2 \mathrm{M} \mathrm{NH}_{4} \mathrm{H}_{2} \mathrm{PO}_{4}, 20 \%$ (w/v) PEG 3350, 0.1 M HEPES, pH 7.5, in crystallization solution supplemented with >10 mM 4-nitrophenyl-2-fluoroacetyl- $\beta$-D-galactosaminide. Crystals of the CpNga123 double mutant in complex with the Gb4 disaccharide were obtained by soaking crystals grown in $0.24 \mathrm{M}$ sodium formate, $18 \%$ (w/v) polyethylene glycol 3350, 0.1 M HEPES, pH 7.0, in crystallization solution supplemented with $>10 \mathrm{mM} \mathrm{Gb} 4$ disaccharide. Crystals of the CpNga123 double mutant in complex with GA2 were obtained by soaking crystals grown in $0.24 \mathrm{M} \mathrm{NH}_{4} \mathrm{H}_{2} \mathrm{PO}_{4}, 22 \%$ (w/v) polyethylene glycol 3350, 0.1 M HEPES, $\mathrm{pH} 7.5$, in crystallization solution supplemented with 
$>10 \mathrm{mM} \mathrm{GA} 2$. Crystals selected for X-ray analysis were cryoprotected in crystallization solution supplemented with $20 \%$ (v/v) 2-methyl-2,4-pentanediol followed by flash cooling in liquid nitrogen. Data were collected at either the Stanford Synchrotron Radiation Lightsource or the Canadian Light Source as indicated in Table 1.

Diffraction data from crystals of Semet- CpNga123 were collected at a wavelength optimized for anomalous scattering from the incorporated selenium atoms. The data was integrated using XDS 24 and scaling performed with SCALA ${ }^{25}$. Automated heavy atom substructure determination, phasing, and density modification was done using AutoSHARP ${ }^{26}$. A total of 11 selenium positions corresponding to 11 selenomethionine residues in the single monomer present in the asymmetric unit were found and used in the phasing process. BUCCANEER ${ }^{27}$ was used to build an initial model of CpNga123, which was not completed but used to determined the structure of CpNga123 with the higher resolution native data.

Diffraction data from native CpNga123 crystals were processed using MOSFLM to integrate the data, POINTLESS used to identify the space group, and SCALA used to scale and merge the data ${ }^{25,28}$. PHASER was used to identify the placement of two CpNga123 molecules in the asymmetric unit using the initial Semet- $\mathrm{CpNga1} 23$ structure as a search model ${ }^{29}$. Initial phases were determined by refinement of the model generated by molecular replacement with REFMAC 30. ARP/wARP was used for automated model building resulting in a nearly complete model of CpNga123 ${ }^{31}$. Data for all other CpNga123 crystals were processed as for the CpNga123 native data. A monomer from the finalized native structure was used as the starting point to determine the structures.

In all cases, models were completed by iterative manual building in COOT and refinement with REFMAC ${ }^{32}$. The final addition of water molecules was performed in COOT with FINDWATERS and manually checked after refinement. In all data sets, refinement procedures were monitored by flagging $5 \%$ of all observations as "free", 33 . Model validation was 
4498 performed with MOLPROBITY ${ }^{34}$. Data collection, processing, and model refinement statistics 6499 are summarized in Table 1.

7

8

9500 


\section{ACCESSION CODES}

Protein Data Bank: Coordinates and structure factors have been deposited with the following accession codes: CpNga123, 5fqe; CpNga123 GalNAc complex, 5fqf; CpNga123 2FGalNac complex, 5fr0; CpNga123 D344N/E345Q GA2 complex, 5fqh; CpNga123 D344N/E345Q Gb4 disaccharide complex, 5fqg.

\section{ACKNOWLEDGEMENTS}

This research was supported by a Canadian Institute of Health Research operating grant (MOP 130305). We thank the staff at the Canadian Light Source (CLS) and the Stanford Synchrotron Radiation Lightsource (SSRL) beamlines where diffraction data were collected. The CLS is supported by the Natural Sciences and Engineering Research Council of Canada, the National 514 Research Council Canada, the Canadian Institutes of Health Research, the Province of 515 Saskatchewan, Western Economic Diversification Canada, and the University of Saskatchewan. 516 SSRL is a Directorate of SLAC National Accelerator Laboratory and an Office of Science User 517 Facility operated for the U.S. DOE Office of Science by Stanford University. The SSRL 518 Structural Molecular Biology Program is supported by the DOE Office of Biological and 519 Environmental Research, and by the National Institutes of Health, National Center for Research 520 Resources, Biomedical Technology Program (P41RR001209), and the National Institute of 521 General Medical Sciences. DVJ is the Canada Research Chair in Chemical Glycobiology. 


\section{FIGURE LEGENDS}

Figure 1. Thin layer chromatography analysis of CpNga123 activity. (A) Screening of CpNga123 activity on various glycans. (-) indicates sample incubated without enzyme; $(+)$ indicates sample incubated with enzyme. Glycan abbreviations are as follows: Gb4, $\beta$-DGalNAc-( $1 \rightarrow 3)-\alpha$-D-Gal-( $1 \rightarrow 4)-\beta$-D-Gal-( $1 \rightarrow 4) \square \beta$-D-Glc; Gb5, $\beta$-D-Gal-( $1 \rightarrow 3) \square \beta$-D-GalNAc$(1 \rightarrow 3)-\alpha-D-G a l-(1 \rightarrow 4)-\beta-D-G a l-(1 \rightarrow 4) \square \beta$-D-Glc; GA1, $\beta$-D-Gal-( $1 \rightarrow 3)-\beta$-D-GalNAc-( $1 \rightarrow 4)-\beta$ D-Gal-( $1 \rightarrow 4) \square \beta$-D-Glc]; GA2, $\beta$-D-GalNAc-( $1 \rightarrow 4)$ - $\beta$-D-Gal-( $1 \rightarrow 4) \square \beta$-D-Glc; BHIV, $\alpha$-L-Fuc$(1 \rightarrow 2)-\beta$-D-Gal-( $(1 \rightarrow 3)-\beta$-D-GalNAc- $(1 \rightarrow 3) \square \beta$-D-Gal; $\quad$ BGAII, $\alpha$-D-GalNAc- $(1 \rightarrow 3)[\alpha-L-F u c-$ $(1 \rightarrow 2)]-\beta$-D-Gal-( $1 \rightarrow 4) \square \beta$-D-Gal $\}$. (B) Analysis of degradation products by TLC. Lactose is $\beta$ D-Gal-( $1 \rightarrow 4) \square \beta$-D-Glc while Gb3 is $\alpha$-D-Gal-( $1 \rightarrow 4)-\beta$-D-Gal-( $1 \rightarrow 4) \square \beta$-D-Glc. GalNAc did not stain using the sulfuric acid/ethanol development.

Figure 2. Schematic representation of the $\mathrm{CpNga1} 23$ crystal structure. (A) The $\mathrm{N}$-terminal $\beta$ sandwich is shown in yellow, the $(\beta / \alpha)_{8}$-barrel in purple, and the C-terminal $\alpha$-helical domain in blue. The $\mathrm{N}$ - and $\mathrm{C}$-termini are indicated. The locations of the main and minor GalNAc binding sites are shown with GalNAc residues in green and blue colored sticks, respectively. The pink loop regions represent the portion of the enzyme that undergoes structural changes upon substrate recognition. This region contains $\beta$-strand and $\alpha$-helix secondary structures, the coloring of which is maintained with the rest of the $(\beta / \alpha)_{8}$-barrel. Expansions show (the main GalNAc binding site (B) and the minor GalNAc binding site (C). In each panel, the carbohydrate is shown as sticks surrounded by blue mesh that represents maximum-likelihood $\sigma_{\mathrm{a}}$-weighted $F_{o^{-}}$ $F_{c}$ electron density maps contoured at $3 \sigma$. Residues involved in carbohydrate recognition are shown as orange sticks. Putative catalytic residues are shown as blue sticks. Water molecules are shown as red spheres and hydrogen bonds as yellow dashes.

Figure 3. The complex of CpNga123 with GalNAc- $\mathrm{F}_{2} \cdot$ GalNAc- $\mathrm{F}_{2}$ is shown as green sticks surrounded by blue mesh that represents maximum-likelihood $\sigma_{\mathrm{a}}$-weighted $F_{o^{-}} F_{c}$ electron density maps contoured at $3 \sigma$. Residues involved in carbohydrate recognition are shown as 
orange sticks. Putative catalytic residues are shown as blue sticks. Hydrogen bonds are shown as yellow dashes.

Figure 4. The complex of CpNga123 with GA2 (A) and the Gb4 disaccharide (B). In all panels the carbohydrate is shown as green sticks surrounded by blue mesh that represents maximumlikelihood $\sigma_{\mathrm{a}}$-weighted $F_{o}-F_{c}$ electron density maps contoured at $3 \sigma$. Residues involved in carbohydrate recognition are shown as orange sticks. Putative catalytic residues are shown as blue sticks. Water molecules are shown as red spheres and hydrogen bonds as yellow dashes.

Figure 6. Conformational changes in $\mathrm{CpNga} 123$ upon engagement of carbohydrate. (A) A structural overlap of CpNga123 in complex with GalNAc-F 2 (yellow) and CpNga123 in complex with GalNAc. The backbone of residues 287-382 are shown in ribbon representation to show their different placement in space. Relevant amino acids are shown as sticks as are the carbohydrates. Arrows are used to highlight important changes in the placement of the indicated amino acids. Panels (B) and (C) show the surface representations of the active site in complex with GalNAc (panel B) and GalNAc-F 2 (panel C) with the surface contributed by the mobile region of the protein colored purple. Panels (D), (E), and (F) show structural representations of the B-factors of the models for the GalNAc complex (panel D), the GA2 complex (panel E), and the GalNAc-F $F_{2}$ complex (panel F). The relative B-factors are represented by color ramping and tube thickness from low (blue and thin tube) to high (red and thick tube). Important secondary structure elements are labeled and the bound carbohydrates are shown as green sticks. The grey arrow indicates the loop comprising amino acids 374-382, which was disordered and therefore not modeled in the GalNAc-F 2 complex. 
2

3

4

5

6

8

(1)

4

(1)

Figure 7. Recognition of intact substrates by CpNga123. (A) A structural overlap of CpNga123 in complex with GalNAc- $\mathrm{F}_{2}$ (shown in purple but with the carbohydrate omitted for clarity) and CpNga123 in complex with the Gb4 disaccharide (orange). (B) A structural overlap of CpNga123 in complex with GalNAc- $F_{2}$ (as shown in panel A) and CpNga123 in complex with GA2 (yellow). The putative catalytic residues are shown as blue sticks for the GalNAc- $F_{2}$

584 complex and D376 in the 374-382 loop is shown as slate sticks. 


\section{REFERENCES}

1. Cantarel, B. L., Coutinho, P. M., Rancurel, C., Bernard, T., Lombard, V. \& Henrissat, B. (2008). The Carbohydrate-Active EnZymes database (CAZy): an expert resource for Glycogenomics. Nucleic Acids Res.

2. Schnaar, R. L., Suzuki, A. \& Stanley, P. (2009). Glycosphingolipids. In Essentials of Glycobiology 2nd edit. (Varki, A., Cummings, R. D., Esko, J. D., Freeze, H. H., Stanley, P., Bertozzi, C. R., Hart, G. W. \& Etzler, M. E., eds.), Cold Spring Harbor (NY).

3. Stubbs, K. A., Macauley, M. S. \& Vocadlo, D. J. (2009). A selective inhibitor GalPUGNAc of human lysosomal beta-hexosaminidases modulates levels of the ganglioside GM2 in neuroblastoma cells. Angew Chem Int Ed Engl 48, 1300-3.

4. Sumida, T., Fujimoto, K. \& Ito, M. (2011). Molecular cloning and catalytic mechanism of a novel glycosphingolipid-degrading beta-N-acetylgalactosaminidase from Paenibacillus sp. TS12. J Biol Chem 286, 14065-72.

5. Zechel, D. L. \& Withers, S. G. (2000). Glycosidase mechanisms: anatomy of a finely tuned catalyst. Acc Chem Res 33, 11-8.

6. Shimizu, T., Ohtani, K., Hirakawa, H., Ohshima, K., Yamashita, A., Shiba, T., Ogasawara, N., Hattori, M., Kuhara, S. \& Hayashi, H. (2002). Complete genome sequence of Clostridium perfringens, an anaerobic flesh-eater. Proc Natl Acad Sci U S A 99, 996-1001.

7. Myers, G. S., Rasko, D. A., Cheung, J. K., Ravel, J., Seshadri, R., DeBoy, R. T., Ren, Q., Varga, J., Awad, M. M., Brinkac, L. M., Daugherty, S. C., Haft, D. H., Dodson, R. J., Madupu, R., Nelson, W. C., Rosovitz, M. J., Sullivan, S. A., Khouri, H., Dimitrov, G. I., Watkins, K. L., Mulligan, S., Benton, J., Radune, D., Fisher, D. J., Atkins, H. S., Hiscox, T., Jost, B. H., Billington, S. J., Songer, J. G., McClane, B. A., Titball, R. W., Rood, J. I., Melville, S. B. \& Paulsen, I. T. (2006). Skewed genomic variability in strains of the toxigenic bacterial pathogen, Clostridium perfringens. Genome Res 16, 1031-40.

8. Ficko-Blean, E., Gregg, K. J., Adams, J. J., Hehemann, J. H., Czjzek, M., Smith, S. P. \& Boraston, A. B. (2009). Portrait of an enzyme: A complete structural analysis of a multimodular beta -N-acetylglucosaminidase from Clostridium perfringens. J Biol Chem. 284, 9876-84.

9. Holm, L. \& Sander, C. (1993). Protein structure comparison by alignment of distance matrices. J Mol.Biol. 233, 123-138.

10. Knight, S. D., Choudhury, D., Hultgren, S., Pinkner, J., Stojanoff, V. \& Thompson, A. (2002). Structure of the S pilus periplasmic chaperone SfaE at 2.2 A resolution. Acta Crystallogr D Biol Crystallogr 58, 1016-22.

11. Vasella, A., Davies, G. J. \& Bohm, M. (2002). Glycosidase mechanisms. Curr Opin Chem Biol 6, 619-29.

12. van Aalten, D. M., Komander, D., Synstad, B., Gaseidnes, S., Peter, M. G. \& Eijsink, V. G. (2001). Structural insights into the catalytic mechanism of a family 18 exo-chitinase. Proc Natl Acad Sci U S A 98, 8979-84.

13. Markovic-Housley, Z., Miglierini, G., Soldatova, L., Rizkallah, P. J., Muller, U. \& Schirmer, T. (2000). Crystal structure of hyaluronidase, a major allergen of bee venom. Structure 8, 1025-35. 
14. Mark, B. L., Vocadlo, D. J., Knapp, S., Triggs-Raine, B. L., Withers, S. G. \& James, M. N. (2001). Crystallographic evidence for substrate-assisted catalysis in a bacterial betahexosaminidase. J Biol Chem 276, 10330-7.

15. Dennis, R. J., Taylor, E. J., Macauley, M. S., Stubbs, K. A., Turkenburg, J. P., Hart, S. J., Black, G. N., Vocadlo, D. J. \& Davies, G. J. (2006). Structure and mechanism of a bacterial beta-glucosaminidase having O-GlcNAcase activity. Nat Struct Mol Biol 13, 365-71.

16. Robb, M., Robb, C. S., Higgins, M. A., Hobbs, J. K., Paton, J. C. \& Boraston, A. B. (2015). A second beta-hexosaminidase encoded in the Streptococcus pneumoniae genome provides an expanded biochemical ability to degrade host glycans. J Biol Chem. In press.

17. Anderson, K. M., Ashida, H., Maskos, K., Dell, A., Li, S. C. \& Li, Y. T. (2005). A clostridial endo-beta-galactosidase that cleaves both blood group A and B glycotopes: the first member of a new glycoside hydrolase family, GH98. J Biol Chem 280, 7720-8.

18. Ficko-Blean, E. \& Boraston, A. B. (2012). Structural analysis of a bacterial exo- $\alpha-D-N-$ acetylglucosaminidase in complex with an unusual disaccharide found in class III mucin. Glycobiology 22, 590-5.

19. Fujita, M., Tsuchida, A., Hirata, A., Kobayashi, N., Goto, K., Osumi, K., Hirose, Y., Nakayama, J., Yamanoi, T., Ashida, H. \& Mizuno, M. (2011). Glycoside hydrolase family 89 alpha-N-acetylglucosaminidase from Clostridium perfringens specifically acts on GlcNAc alpha1,4Gal beta1R at the non-reducing terminus of O-glycans in gastric mucin. J Biol Chem 286, 6479-89.

20. Newstead, S. L., Potter, J. A., Wilson, J. C., Xu, G., Chien, C. H., Watts, A. G., Withers, S. G. \& Taylor, G. L. (2008). The structure of Clostridium perfringens NanI sialidase and its catalytic intermediates. J Biol Chem 283, 9080-8.

21. Rose, M. C., Voter, W. A., Sage, H., Brown, C. F. \& Kaufman, B. (1984). Effects of deglycosylation on the architecture of ovine submaxillary mucin glycoprotein. $J$ Biol Chem 259, 3167-72.

22. Pluvinage, B., Chitayat, S., Ficko-Blean, E., Abbott, D. W., Kunjachen, J. M., Grondin, J., Spencer, H. L., Smith, S. P. \& Boraston, A. B. (2013). Conformational Analysis of $\mathrm{StrH}$, the Surface-Attached exo- $\beta$-D-N-Acetylglucosaminidase from Streptococcus pneumoniae. Journal of Molecular Biology 425, 334-349.

23. Gasteiger, E., Gattiker, A., Hoogland, C., Ivanyi, I., Appel, R. D. \& Bairoch, A. (2003). ExPASy: The proteomics server for in-depth protein knowledge and analysis. Nucleic Acids Res 31, 3784-8.

24. Kabsch, W. (2010). Xds. Acta Crystallogr D Biol Crystallogr 66, 125-32.

25. Evans, P. (2006). Scaling and assessment of data quality. Acta Crystallogr D Biol Crystallogr 62, 72-82.

26. Vonrhein, C., Blanc, E., Roversi, P. \& Bricogne, G. (2007). Automated structure solution with autoSHARP. Methods Mol Biol 364, 215-30.

27. Cowtan, K. (2006). The Buccaneer software for automated model building. 1. Tracing protein chains. Acta Crystallogr D Biol Crystallogr 62, 1002-11.

28. Leslie, A. G. (2006). The integration of macromolecular diffraction data. Acta Crystallogr D Biol Crystallogr 62, 48-57.

29. McCoy, A. J., Grosse-Kunstleve, R. W., Adams, P. D., Winn, M. D., Storoni, L. C. \& Read, R. J. (2007). Phaser crystallographic software. J Appl Crystallogr 40, 658-674. 
2

3

$\begin{array}{ll}4 & 675\end{array}$

676

7677

8678

9679

30. Murshudov, G. N., Vagin, A. A. \& Dodson, E. J. (1997). Refinement of macromolecular structures by the maximum likelihood method. Acta Cryst.D 53, 240-255.

31. Langer, G., Cohen, S. X., Lamzin, V. S. \& Perrakis, A. (2008). Automated macromolecular model building for X-ray crystallography using ARP/wARP version 7 . Nat Protoc 3, 1171-9.

32. Emsley, P. \& Cowtan, K. (2004). Coot: model-building tools for molecular graphics. Acta Crystallogr D Biol Crystallogr 60, 2126-32.

33. Brunger, A. T. (1992). Free R value: a novel statistical quantity for assessing the accuracy of crystal structures. Nature 355, 472-475.

34. Chen, V. B., Arendall, W. B., Headd, J. J., Keedy, D. A., Immormino, R. M., Kapral, G. J., Murray, L. W., Richardson, J. S. \& Richardson, D. C. (2010). MolProbity: all-atom structure validation for macromolecular crystallography. Acta Crystallographica Section D-Biological Crystallography 66, 12-21. 
${ }^{\star}$ Graphical Abstract

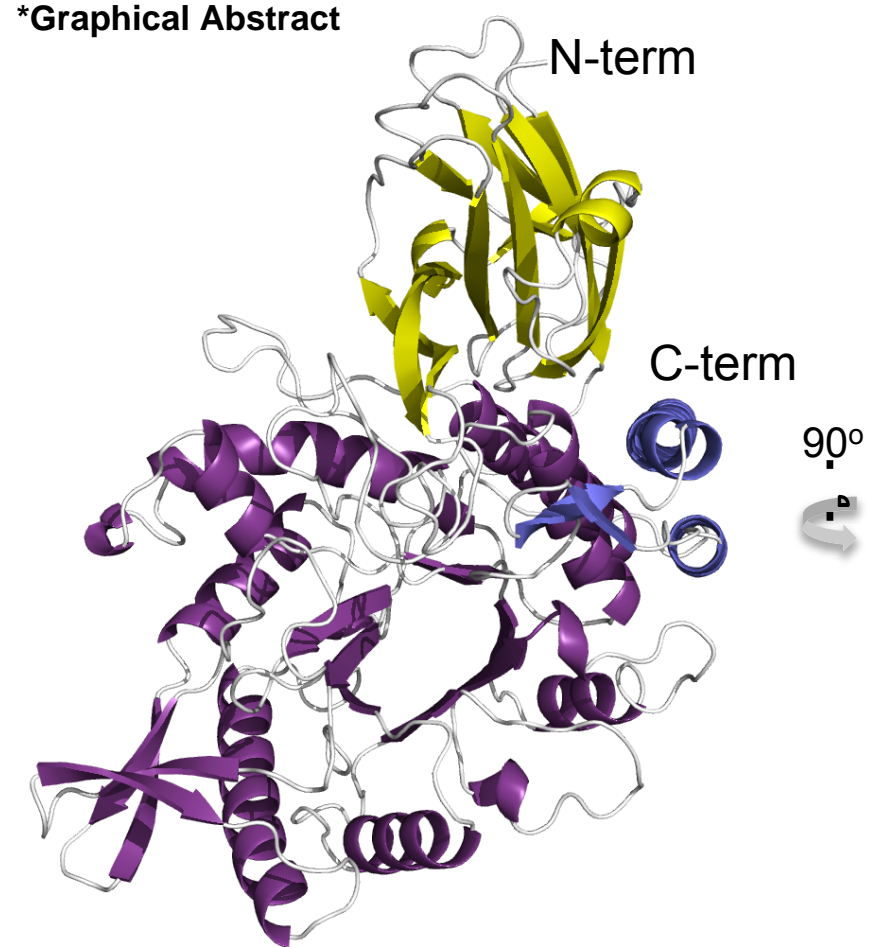

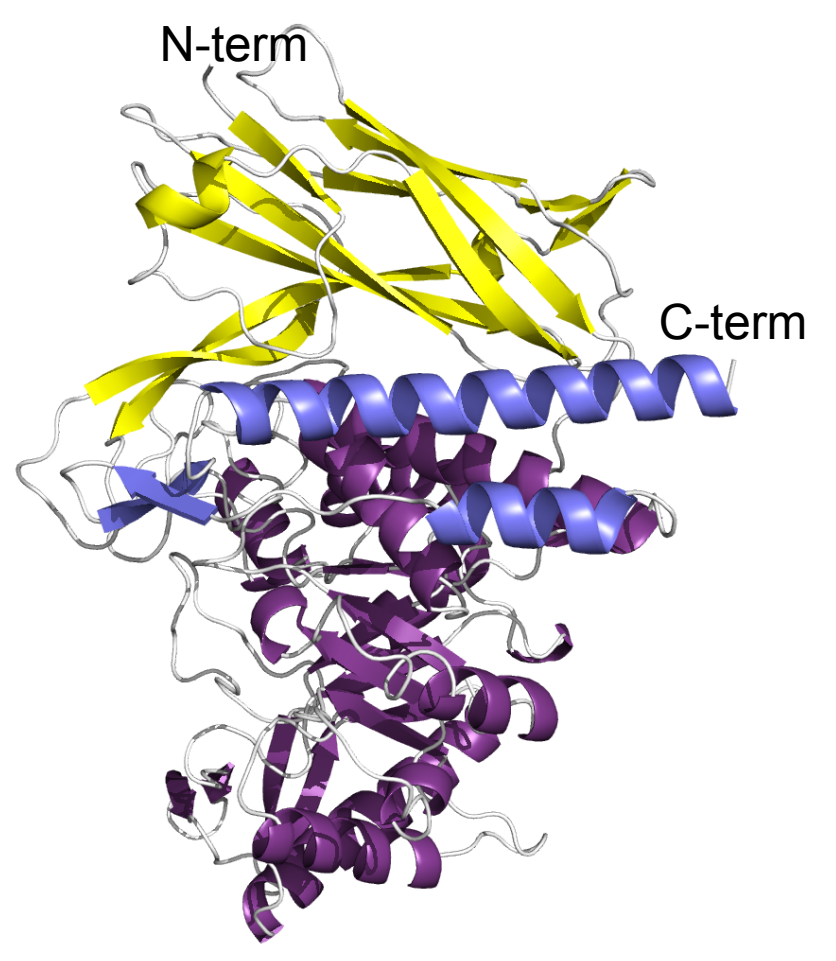


Table 1: X-ray data collection and structure statistics.

\begin{tabular}{|c|c|c|c|c|c|c|}
\hline & CpNga123 & CpNga123 WT & CpNga123 WT & $\begin{array}{c}\text { CpNga123 } \\
\text { D344N/E345Q }\end{array}$ & $\begin{array}{c}\text { CpNga123 } \\
\text { D344N/E345Q }\end{array}$ & CpNga123 WT \\
\hline & Seleno-methionine derivative & Native & GalNAc complex & Gb4 disaccharide & GA2 & GalNAc- $\mathrm{F}_{2}$ \\
\hline \multicolumn{7}{|l|}{ Data Collection } \\
\hline Beamline & CLS 08ID-1 & CLS 08ID-1 & SSRL BL 7-2 & CLS 08ID-1 & CLS 08ID-1 & CLS 08ID-1 \\
\hline Wavelength $(\AA)$ & 0.9739 & 0.97957 & 1.12709 & 0.98400 & 0.98400 & 0.98400 \\
\hline Space Group & $\mathrm{P} 33_{2} 21$ & $\mathrm{P} 2{ }_{1} 2_{1} 2_{1}$ & $\mathrm{P} 2{ }_{1} 2_{1} 2_{1}$ & $\mathrm{P} 33_{2} 21$ & $\mathrm{P} 3{ }_{2} 21$ & $\mathrm{P} 3221$ \\
\hline \multicolumn{7}{|l|}{ Cell Dimensions } \\
\hline$a, b, c(\AA)$ & $114.1,114.1,97.1$ & $80.4,115.0,135.5$ & $80.5,114.8,134.7$ & $113.3,113.3,96.0$ & $111.1,111.1,95.8$ & $99.5,99.5,95.3$ \\
\hline Resolution $(\AA)$ & $49.92-2.75(2.90-2.75)$ & $87.7-1.50(1.54-1.50)$ & $70.0-2.15(2.27-2.15)$ & $68.0-2.30(2.42-2.30)$ & $48.1-2.10(2.16-2.10)$ & $47.7-1.75(1.78-1.75)$ \\
\hline $\mathrm{R}_{\text {merge }}$ & $0.079(0.507)$ & $0.051(0.406)$ & $0.144(0.497)$ & $0.104(0.686)$ & $0.089(0.733)$ & $0.107(0.481)$ \\
\hline$\langle\mathrm{I} / \sigma \mathrm{I}\rangle$ & $19.5(3.6)$ & $16.2(2.6)$ & $10.0(3.8)$ & $16.7(4.2)$ & $15.2(2.9)$ & $14.7(2.6)$ \\
\hline Completeness (\%) & $100.0(100.0)$ & $98.8(99.4)$ & $99.8(99.9)$ & $100.0(100.0)$ & $99.5(99.2)$ & $100.0(100.0)$ \\
\hline Redundancy & $6.6(6.7)$ & $4.9(3.4)$ & $6.7(6.8)$ & $15.2(15.0)$ & $10.8(11.0)$ & $12.6(8.2)$ \\
\hline No. of reflections & 127781 & 1026529 & 481969 & 487979 & 432901 & 699289 \\
\hline No. Unique & 19385 & 209500 & 72256 & 32038 & 39970 & 55369 \\
\hline \multicolumn{7}{|l|}{ Refinement } \\
\hline Resolution $(\AA)$ & & 1.50 & 2.15 & 2.30 & 2.10 & 1.75 \\
\hline $\mathrm{R}_{\text {work }} / \mathrm{R}_{\text {free }}$ & & $0.16 / 0.19$ & $0.15 / 0.20$ & $0.23 / 0.27$ & $0.18 / 0.24$ & $0.18 / 0.22$ \\
\hline \multicolumn{7}{|l|}{ No. of atoms } \\
\hline Protein & & 4886 (A), 4856 (B) & 4814 (A), 4769 (B) & 4723 & 4693 & 4651 \\
\hline Ligand & & $\begin{array}{c}12 \text { (FMT), } 133 \text { (BR), } \\
8 \text { (MPD) }\end{array}$ & $\begin{array}{c}30 \text { (GalNAc-A), } \\
30 \text { (GalNAc-B), } 45 \\
\text { (FMT) }\end{array}$ & $\begin{array}{l}26(\mathrm{~Gb} 4), \\
12(\mathrm{FMT})\end{array}$ & $37(\mathrm{GA} 2), 5\left(\mathrm{PO}_{4}\right)$ & $17($ GalNAc-F $), 5\left(\mathrm{PO}_{4}\right)$ \\
\hline Water & & 1277 & 807 & 194 & 166 & 415 \\
\hline \multicolumn{7}{|l|}{$B$-factors } \\
\hline Protein & & $15.2(\mathrm{~A}), 16.6(\mathrm{~B})$ & 20.4 (A), 23.4 (B) & 48.3 & 47.0 & 35.8 \\
\hline Ligand & & $\begin{array}{c}39.6 \text { (FMT), } 29.3 \text { (BR), } \\
35.5 \text { (MPD) }\end{array}$ & $\begin{array}{c}33.1 \text { (GalNAc-A), } 33.0 \\
\text { (GalNAc-B), } 43.2 \text { (FMT) }\end{array}$ & $\begin{array}{c}49.0 \text { (GalNAc } \beta 1-3 \mathrm{Gal}) \\
52.2 \text { (FMT) }\end{array}$ & $\begin{array}{c}58.6(\mathrm{GalNAc} \beta 1-4 \mathrm{Gal} \\
\beta 1-4 \mathrm{Glc}), 60.5\left(\mathrm{PO}_{4}\right)\end{array}$ & $\begin{array}{c}44.1\left(\mathrm{GalNAc}-\mathrm{F}_{2}\right), 46.7 \\
\left(\mathrm{PO}_{4}\right)\end{array}$ \\
\hline Water & & 26.9 & 27.1 & 41.5 & 43.9 & 38.2 \\
\hline \multicolumn{7}{|l|}{ r.m.s.d } \\
\hline Bond lengths $(\AA)$ & & 0.017 & 0.017 & 0.008 & 0.012 & 0.016 \\
\hline Bond angles $\left({ }^{\circ}\right)$ & & 1.726 & 1.742 & 1.288 & 1.466 & 1.640 \\
\hline \multicolumn{7}{|l|}{ Ramachandran } \\
\hline & & & & & & \\
\hline Preferred & & 97.7 & 97.2 & 96.6 & 95.5 & 95.8 \\
\hline Generously allowed & & 2.1 & 2.6 & 3.2 & 4.3 & 4.0 \\
\hline Disallowed & & 0.2 & 0.2 & 0.2 & 0.2 & 0.2 \\
\hline
\end{tabular}




$\frac{-}{\mathrm{GA} 1} \quad \frac{+}{\mathrm{GA} 2} \quad \frac{-}{\mathrm{Gb} 4} \quad \frac{-}{\mathrm{Gb} 5} \quad \frac{-}{\mathrm{BGHIV}} \quad \frac{-}{\mathrm{BGAII}}$

B
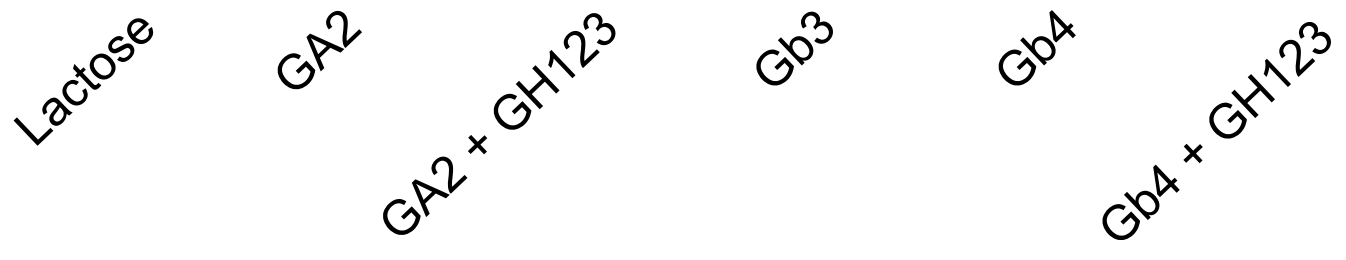

\section{Figure 1}

$0^{2}$

$$
\text { . }
$$


Fjgure 2
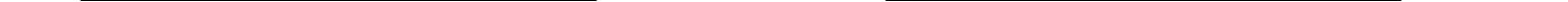


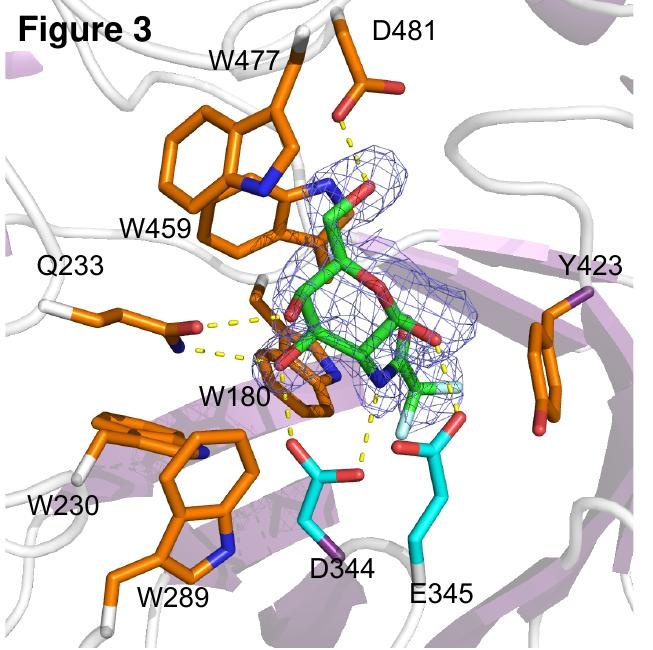


Figure 4
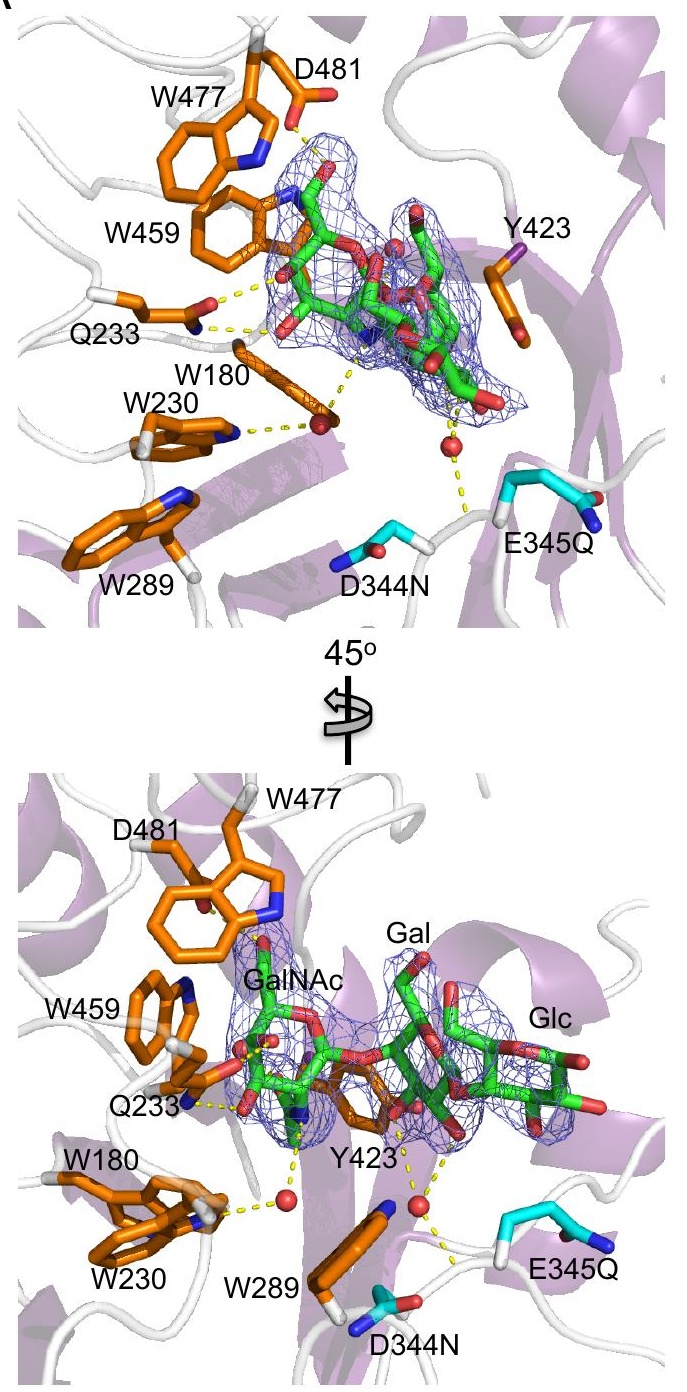

B

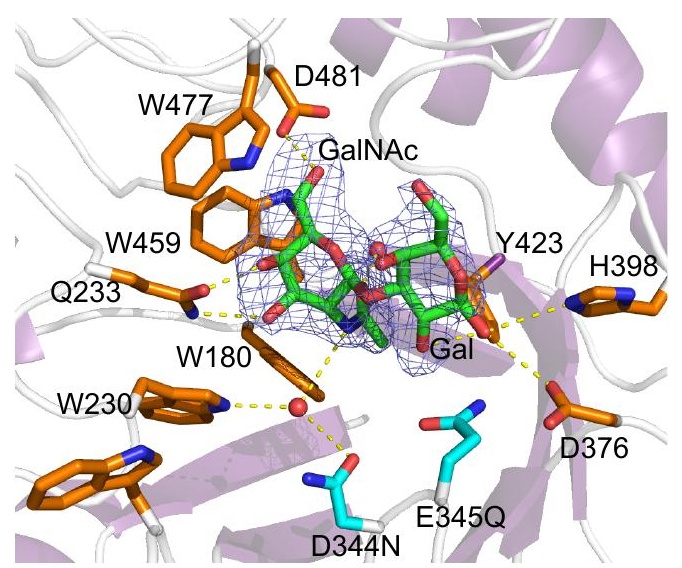




\section{Figure 5}

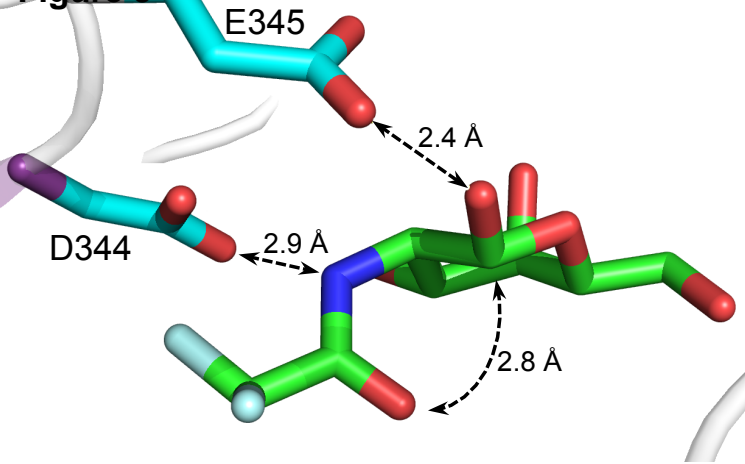


Figure 6

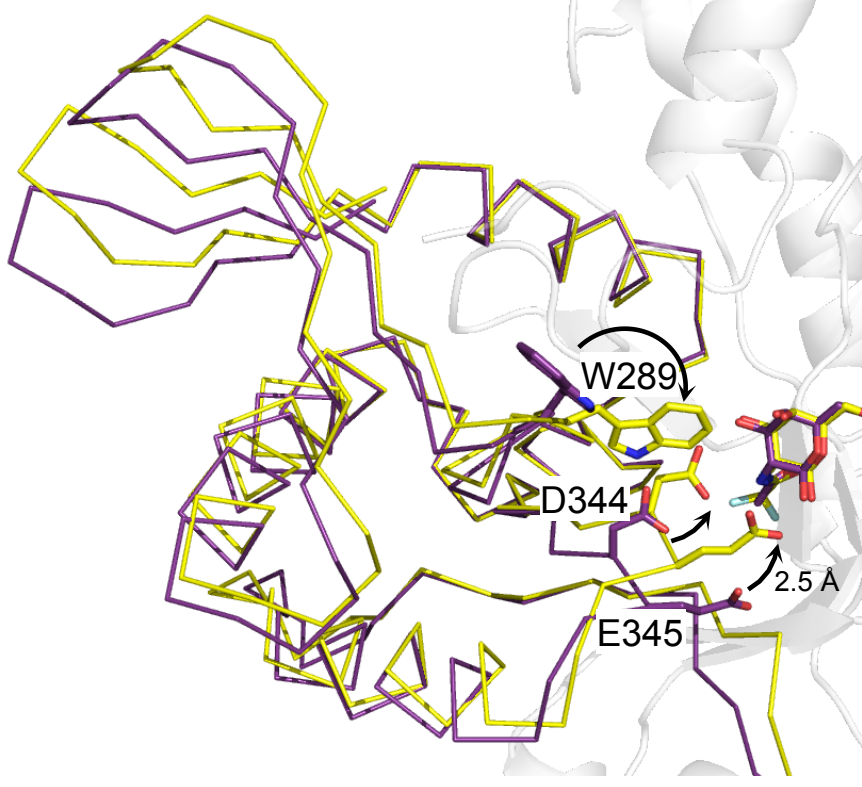

D

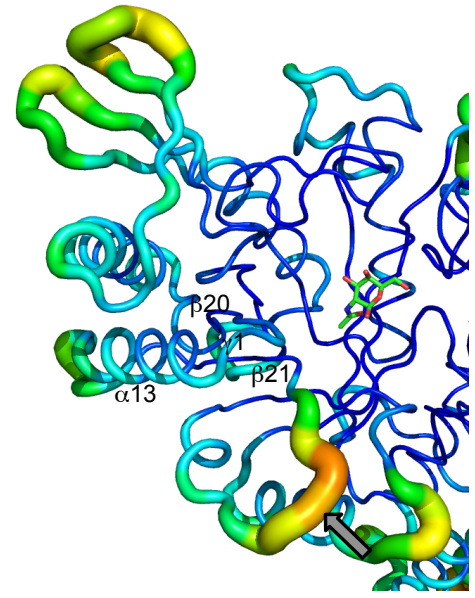

B
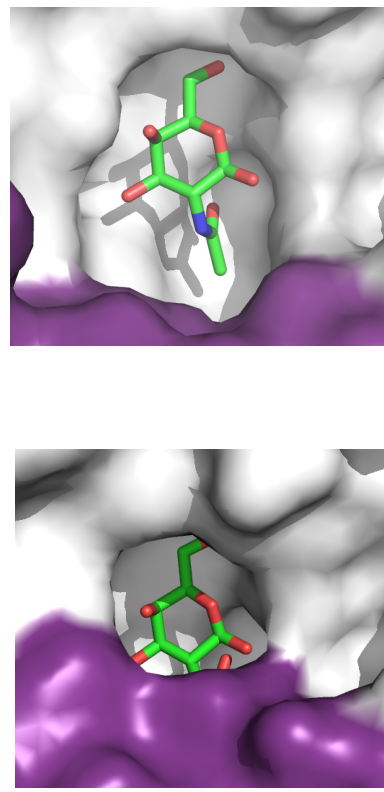

F

\section{C}
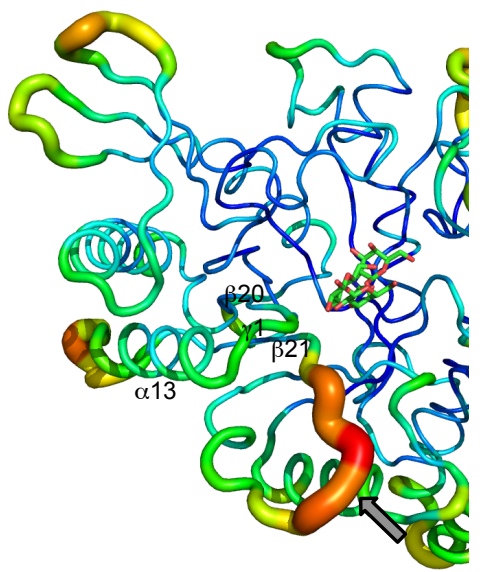

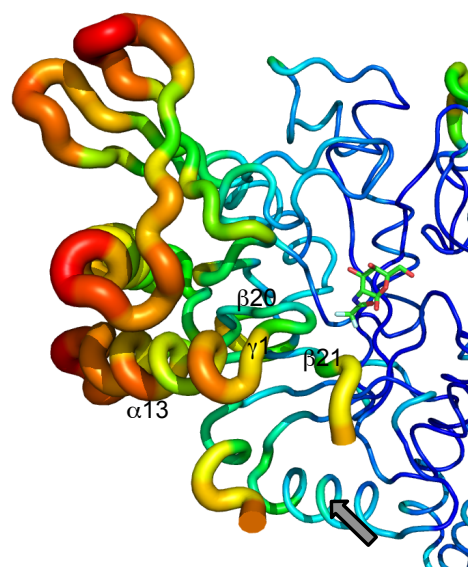


Figure 7

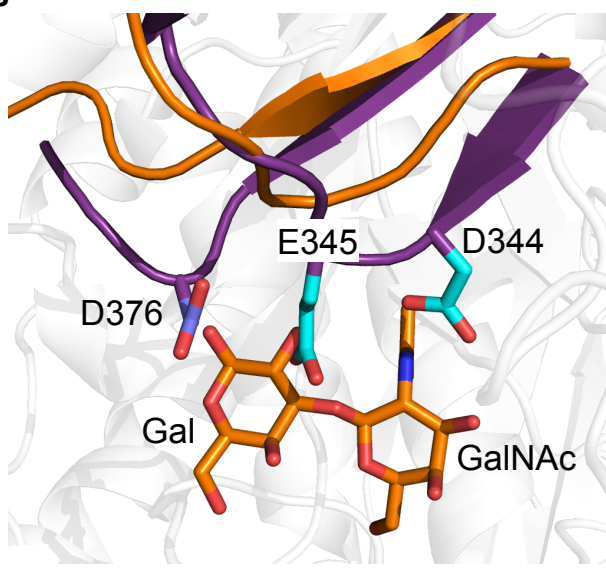

B
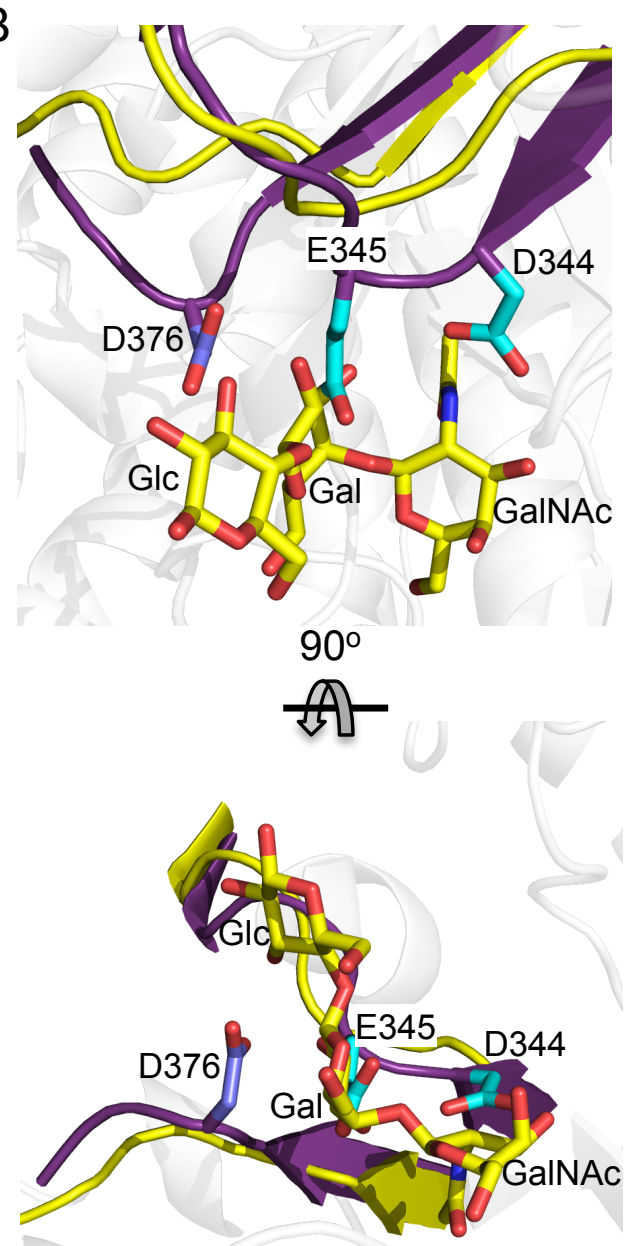